\title{
Right Atrial Myxoma in a Child with Nephrotic Syndrome - A Rare Event
}

\author{
RANJIT RANJAN ROY ${ }^{1}$, ISHRAT JAHAN ${ }^{2}$, ABDULLAHAL MAMUN ${ }^{2}$
}

\section{Introduction:}

Nephrotic syndrome (NS) is a common childhood kidney disease characterized by massiveproteinuria $\left(>1 \mathrm{gm} / \mathrm{m}^{2} /\right.$ day), hypoalbuminemia $(<2.5 \mathrm{~g} / \mathrm{dl})$, generalized edema and hypercholesterolemia. ${ }^{1}$

Very rarely childhood NS may be associated with various benign tumor like atrial myxoma, rhabdomyoma and fibroma. Among them atrial myxoma is the commonest and also in the right atrium is not common site for myxoma like left atrium. Usually right atrial site is three to four time less affected by this benign tumor. ${ }^{2}$ Myxoma, a primary cardiac tumour is a raredisease, especially in children. Right atrial myxoma was first reported in $1908 .{ }^{3}$ Approximately $75 \%$ of sporadic myxomas occur in females. In a series of 66 cardiac myxomas, the female to male ratio is 2.7: 1.4

Majority of the patients with atrial myxoma present with one or more symptoms of clinical triad of embolic events, intracardiac obstruction or nonspecific manifestations with constitutional symptoms. ${ }^{5}$ Myxomas can also be an incidental finding during routine medical checkup of asymptomatic healthy people, especially if they are of small size. ${ }^{6}$

Here is a report of right atrial myxoma in a boy with Nephrotic syndrome, which is very rare in common clinical practice.

\section{Case Report}

A 3 year 6 months old boy was admitted in the department of pediatric nephrology, Bangabandhu Sheikh Mujib Medical university with the complaints of generalized swelling, scanty micturition and precipitation of urine for seven days. On examination, he was found to be puffy, afebrile, anicteric, edematous, normotensive. His vital signs were within normal limit. His bed side urine for albumin byheat coagulation test was 4+. Genitourinary system examination revealed, distended abdomen, full flanks,

1. Associate professor, Department of Pediatric Nephrology, Bangabandhu Sheikh Mujib Medical University

2. Resident, phase-B, Department of Pediatric nephrology, Bangabandhu Sheikh Mujib Medical University

Correspondence: Dr. Ranjit Ranjan Roy, ranjit.bsmmu@gmail.com umbilicus centrally placed and everted, kidneys not ballotable, bladder not palpable. Ascites was present, evident by fluid thrill and shifting dullness and genitalia was normal.On cardiovascular system examination no other physical abnormality was detected except a soft diastolic murmur, grade $2 / 6$ at the left second inter-costal space lateral to the sternal border. But the murmur was not persistent all the time and the intensity of murmur sometime fades or absent specially with change of posture. Other systems revealed no abnormality.

During initial episode of nephrotic syndrome (NS) the boy was treated with corticosteroid in divided dose and the boy responded well. Treatment was complete in context of urinary remission and biochemical parameters during initial 6 weeks therapy. But just before starting alternate day therapy he again developed massive proteinuria and edema.

A 2-D M modeDoppler echocardiographywas done which revealed, a large myxoma(size : $22 \times 19 \mathrm{~mm}$ ) within right atrium protruding through the tricuspid valve towards right ventricle. Other investigations showed, $\mathrm{Hb}-11 \mathrm{gm} / \mathrm{dl}$, ESR- $90 \mathrm{~mm}$ at $1^{\text {st }}$ hour, WBC- $11500 /$ $\mathrm{mm}^{3}$, Urine R/M/E- pus cell: 0-2, Protein-,+++ RBCNil, Serum albumin- $1.2 \mathrm{gm} / \mathrm{dl}$, Spot protein creatinine ratio- 8.8 and Blood and Urine culture revealed no growth of bacteria.

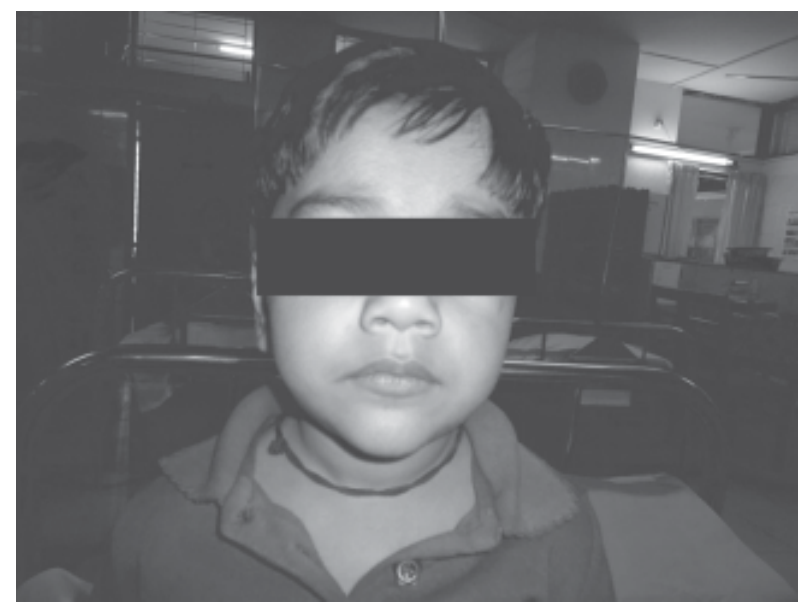

Fig.-1 


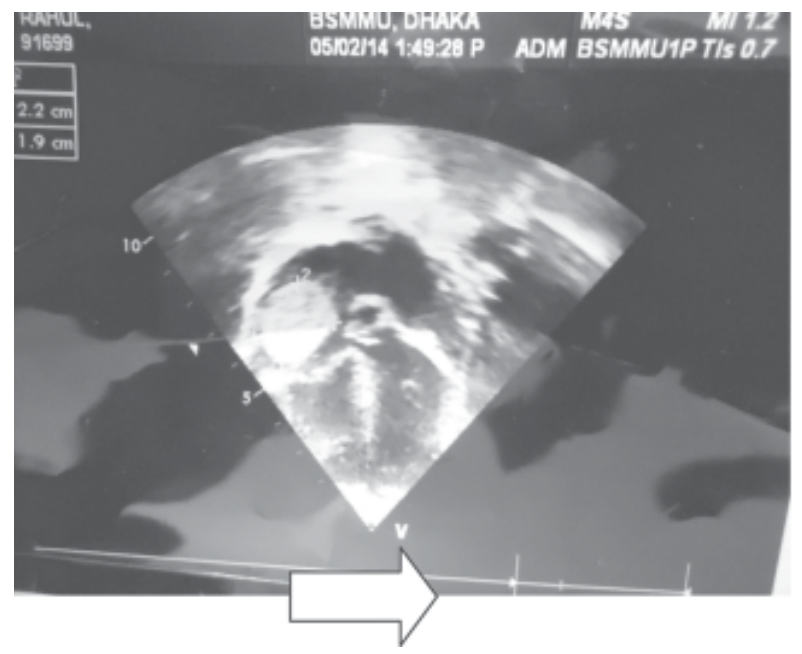

Fig.-2: Echocardiography shows right atrial myxoma

The patient was treated with usual regimen of $1^{\text {st }}$ relapse with oral prednisolone $60 \mathrm{mg} / \mathrm{m}^{2} /$ day and he began to respond. In the mean-time, pediatric cardiologist and cardiac surgeon were consulted for immediate management of myxoma as fatal sequele might occur due to dislodgement of the myxoma. As per advice of cardiac surgeon the boy was transferred to cardiac surgery department of the same institutionfor immediate surgical removal of the mass. But unfortunately three days after transfer the patient expired due to sudden deterioration of the general condition.

\section{Discussion}

Atrial myxoma is most frequently detected in patients in the third or fourth decade of their lives. ${ }^{7}$ Reported patient was only 3 years 6 months old. It is well known that myxoma is more common in females than males and in left atrium than right atrium. ${ }^{2}$ But in the reported case the patient was a boy and had right atrial myxoma.

The presentation of atrial myxoma with proteinuria and haematuria in the absence of any other clinical signs or symptoms is very unusual. ${ }^{8}$ Myxoma usually present withweight loss, raised body temperature, dyspnea after exertion, fatigue, pains and dizziness, supraventricular tachycardia but in this case, the patient was asymptomatic. Physical examination may reveal systolic or diastolic heart murmurs. This patient had only diastolic murmur without any of above mentioned symptoms and signs. Some myxomas can induce inflammatory state, confirmed in laboratory tests(increased ESR, leucocytosis), as well as anaemia, thrombocytopenia or thrombocytosis.
Fragmentations of the tumour may cause embolism of peripheral blood vessels. ${ }^{9}$ The occurrence of general symptoms is associated with the production of cytokines by the tumour, especially of interleukin 6 (IL-6). ${ }^{7}$ In the present case there was only raised ESR (90 $\mathrm{mm}$ at $1^{\text {st }}$ hour) in this case which may be due to nephrotic syndrome as well as myxoma.

Relation between atrial myxoma and nephrotic syndrome is not well described in text and literature. James R. Bushnell et al. ${ }^{8}$ reported an unusual case of atrial myxoma with microscopic hematuria and proteinuria. where urinary signs were resolved after surgical excision of the tumour. Kalra et al. ${ }^{10}$ also described a patient with myxoma presenting with right heart failure and nephrotic range proteinuria. Other recognized causes of proteinuria in patients with cardiac myxomas include membranous nephropathy ${ }^{11}$, amyloidosis ${ }^{12}$, interstitial nephritis ${ }^{13}$ and cryglobulinaemia. ${ }^{14}$

Patients with myxomas have been shown to have detectable anti-endothelial cell antibodies (AECA) in peripheral circulation. ${ }^{15} \mathrm{In}$ animal models, the development of AECA caused renal injury and proteinuria. ${ }^{16}$ Cardiac myxomas also secrete IL-6 which may have a role in the development of renal injury and proteinuria. ${ }^{17} \mathrm{IL}-6$ induces the production of acute phase proteins in hepatocytes and promotes differentiation of $B$ cells, as well as activates macrophages, $T$ cells and B cells. Population based studies in type 1 diabetes have correlated elevated IL-6 levels with the development of gross proteinuria. ${ }^{18}$ This patient relapsed before completing steroid for first attack which is unusual, it may be IL-6 triggered relapse due to myxoma.

\section{Conclusion}

Though right atrial myxomain childhood nephrotic syndrome is a rare event but in case of newly detected systolic murmur in nephrotic syndrome, atrial myxoma should be kept in mind and intervened as early as possible by surgical removal of the myxoma. Otherwise fatal complication may occur.

\section{References}

1. Gordillo R, Spitzer A. The Nephrotic Syndrome. Pediatrics in Review 2009; 30:94

2. Fallon JT, Dec GW. Cardiac tumors. In: Eagle KA (ed). The practice of cardiology, $2^{\text {nd }}$ edition. Boston: Little Brown Company, 1989;1013-29.

3. Battellinia R, Bossertb T, Aretaa M, Naviaa D. Successful surgical treatment of a right atrial myxoma complicated by pulmonary embolism. Interactive Cardiovascular and Thoracic Surgery 2003;2: 555-57 
4. Zheng JJ, Geng XG, Wang HC, Yany Wang HY. Clinical and histopathological analysis of 66 cases with cardiac myxoma. Asian Pac J Cancer Prev 2013; 14: 1743-6

5. St John Sutton MG, Mercier L-A, Giuliani ER, Lie JT. Atrial myxomas: a review of clinical experience in 40 patients. Mayo Clin Proc 1980; 55: $371-6$.

6. MH Tay, KW Lau,ZP Ding, CN Lee. An Interesting Case of Left Atrial Myxoma. Singapore Med J 2002;43: 367-68

7. Sabastine MS, Collucci WS, Schoen FS. Primary tumors of the heart. In : Braunwald E, Zipes DP, Libby P (editors). The heart disease. Philadelphia, Saunders Co., 2004:1741—55

8. James R.B, Charles W, Lazarus K. An unusual presentation of atrial myxoma with haematuria and proteinuria. NDT Plus 2011; 4: 124-25

9. Coley C, Lee KR and Steiner M. Complete embolization of a left atrial myxoma resulting in acute lower extremity ischemia. Tex Heart Inst J 2005; 32: 238-40

10. Kalra PA, Raghavan C and Hassan R. Nephroticrange proteinuria associated with right atrial myxoma. Clin Nephrol 1992; 37: 294-96

11. Waki M, Ishimura $E$ and Morii H. A case of membranousglomerulonephritisassociated with gastric cancer. Osaka City Med J 1997; 43: 95-105

12. Wens R, Goffin $Y$ and Pepys MB . Left atrial myxoma associated with systemic AA amyloidosis. Arch Intern Med 1989; 149: 453-54

13. Metz-Kurschel $U$ and Wehr M. Atrial myxoma and signs of autoimmune disease. Dtsch Med Wochenschr 1989; 114: 181-83

14. Takeishi M, Mimori A and Adachi D. A case of fulminant mixed cryoglobulinaemia after atrial myxoma resection. Jpn J Clin Immunol 2001; 24: $168-74$

15. Maisch B. Immunology of cardiac tumours. Thorac Cardiovasc Surg 1990; 38: 157-163

16. Belizna C, Duijvestijn A, Hamidou M and Tervaert JW. Antiendothelial cell antibodies in vasculitis and connective tissue disease. Ann RheumDis 2006; 65: 1545-50

17. Seino $Y$, Ikeda $U$ and Shimada $K$. Increased expression of interleukin 6 mRNA in cardiac myxomas. Br Heart J 1993; 69: 565-67

18. Sahakyan K, Klein BE and Lee KE. Inflammatory and endothelial dysfunction markers and proteinuria in persons with type I diabetes mellitus. Eur J Endocrinol 2010; 162: 1101-05 